\title{
Personal risks of active users in the digital sphere
}

\author{
T. Skripkina* \\ Russian State University for the Humanities, 125993, Moscow, Russia
}

\begin{abstract}
The article presents the results of a study of the personal characteristics of Internet users with different Internet activity.

The main purpose of this research was to study the poorly studied personal characteristics in active users of social networks: selfpresentation, self-esteem and self-confidence in different areas of life, as well as trust in others. It is empirically proven that active Internet users who are prone to Internet addiction have personality traits associated with self-presentation in a virtual environment, unlike ordinary users. They are not inclined to present themselves as a real person, as a rule, they do not put selfies on their pages, instead of photos they use icons, photos of animals, etc. Therefore, they are not prone to self-disclosure. Information about themselves is superficial, sometimes with a pronounced absolute closeness and self-irony.

They are also characterized by self-doubt, low self-esteem, and extremely poor presentation of their personality. In the field of selfconfidence, they are not inclined to trust themselves, especially in the intellectual and professional spheres, their communication needs are frustrated by the contradiction between the expressed need to communicate and the desire to" close " from the interlocutor.
\end{abstract}

\section{Introduction}

The life of a modern person without a computer and the Internet is almost impossible to imagine. Internet technologies are rapidly developing, and the younger generation is actively involved in them. The younger generation develops in a new socio-cultural and semiotic environment, which, of course, changes the features of socialization. Many of the problems associated with the leading role of digitalization of children and youth development in the process of growing-up are poorly understood and are of increasing concern to scientists, teachers and parents.

On the one hand, the success of a modern person today directly depends on the ability to use modern information technologies, however, it is well known that information technologies have a significant impact on a person, his ther cognitive sphere, methods of action, as well as personal characteristics and age-related development.

\footnotetext{
*Corresponding author: Skrip@email.ru
} 
Computer technologies, which modern children begin to actively use, starting from the age of 4, can not but generate changes in the psyche in consciousness, in the unconscious, in cognitive and emotional-motivational processes, as well as in the personality as a whole.

This becomes understandable considering this process through the prism of the cultural and historical psychology of L. S. Vygotsky (Vygotsky, 1982-1984), whose ideas imply that constantly complicated signs and semiotic systems contribute to the development of higher mental functions. Thus, this problem opens up new promising areas of research in psychological science. However, not everyone is optimistic about the prospects for the development of computer activity. These studies have become particularly relevant in connection with the emergence of such relatively new phenomena as Internet addiction, gaming, trolling, cyber bullying, and some others, which indicate the existence of negative aspects when using computer technologies.

Currently, the study of the psychological aspects of the influence of the Internet on the human psyche is devoted to numerous works from different branches of psychology: personality psychology, cognitive psychology, clinical psychology, etc. Thus, the forecast of A. E. Voiskunsky being the leading Russian scientist in the field of this direction comes true: "Cyberpsychological problems will gradually "dissolve" in the traditional directions of psychology and will cease to "stand out" in it as something specific, it will cease to be a kind of an "island" in psychological science, since almost all "traditional" spheres of human activity will increasingly include components that are carried out in cyberspace, and such components will turn into a necessary element that will not be emphasized" (Voiskunsky, 2010).

Cyberpsychological science is of great interest for social and psychological research. Given that the Internet is a giant collection of networks united by common rules of communication, where each time a live person is located in front of the computer screen, interacting with hundreds and thousands of the like users. There is no wonder that the Internet environment qualitatively affects the interaction of people, changes the way and features of the perception of information, contributes to the formation of new requirements for reality.

This problem is of particular importance for the younger generation. Modern children live in a different perception of the information space, for them, communication with a peer from another part of the world or instant information on any issue is completely ordinary. Experts also pay attention to the fact that new phenomena are generated in social networks - the formation of a list of virtual friends, the distribution of functions in virtual groups, the peculiarity of Internet content, the generation of authorities, as well as the change in some aspects of identity, which is possible only in virtual space, and many others that occupy the attention of social psychologists. Online games also present a great scope for studying.

The overall picture of the development of a child who grows up surrounded by computers and digital devices is changing. In general, this picture can be reduced to the fact that a modern child develops in a different subject and sign environment, which naturally somehow affects the mechanisms and patterns of his development. Interestingly, Japanese scientists have long identified this phenomenon and gave the name "button psychology" to it. Thus, in general, the use of Internet technologies leads to significant structural and functional changes in the psyche and its activities.

Discussing the problem of the Internet environment, it is impossible not to dwell upon the negative aspects of virtual reality and the risks to the development of personality that are of public concern. This is excessive use of the Internet and, above all, Internet addiction, which is known to lead to a loss of control over one's behavior.

At the same time, it is known that the formation of addiction is not the only negative consequence of the ever-increasing computerization. Studies show that active Internet users have persistent deviations from the norm of some indicators of mental state: anxiety, bad 
mood and decreased activity, which indicates maladaptation, inadequate perception of themselves and the world around them. The anxiety increases with the growing dissonance between the "I am virtual", which can do everything in the virtual world, and the "I am real", which is a simple ordinary person. Only in the virtual world, a person can do everything, he is the leader, the winner, he is the main there. All these experiences of self are lost in the real world, which seems "grey" monotonous and uninteresting, which creates anxiety. It is anxiety that serves as an indicator of the occurrence of addiction: with an increase in anxiety, dependence increases, which, in turn, increases anxiety and so on in a circle.

In foreign psychology and other humanities, Internet addiction, especially among young people, is studied very actively.

There are hundreds of studies on a wide variety of problems, from changes in personality and behavior to serious addictions. Most of the researchers ' interest is focused around several main problems - dependence on computer games and dependence on communication in social networks, and dependence on smartphones. As far as we know, the main focus in the study of addictions to computer games is the problem of the relationship between this type of addiction and aggression, cyberbullying, etc. As for the second type of dependence, the range of interests here is much wider. Here is an example of some research. dedicated to this type of addiction. For example, the recently published Mchelle F. Wright "Exposure to online risk in children and adolescents" examines a huge range of problems caused by Internet addiction in children and adolescents. For example, in a chapter devoted to the study of risky behavior in online contacts and the identification of risk factors among Japanese high school students, it was shown that a low level of commitment to school and a preference for the virtual world are significant predictors of risky behavior in online contacts. In particular, it involves contacts with strangers in the Internet [Ikuko Aoyama]. The article by John D. Ranney shows that the high propensity for self-disclosure and self-expression of adolescents in the digital environment creates the risk of adolescent cyber-exploitation and cyber-victimization, which increases the risk of negative experiences and exacerbates negative socio-emotional consequences [John D. Ranney].

Here, for example, are the results of another article from this book [Michelle F.Wright, 2 Tali Heiman, 3DoritOlenik-Shemesh], which is devoted to the so-called problematic use of the Internet. The article identifies the causes and consequences associated with the use of digital technologies by adolescents. The authors identify multiple correlates that lead to problematic Internet use, among which the authors note demographic, biological and genetic, behavioral, psychological and social, which lead to physical, behavioral, psychological, social and academic consequences.

We will briefly present the results of two more articles from this book. This article is dedicated to the problem of cyber bullying. The authors believe that cyber bullying has significantly greater negative consequences in the adolescent environment than just cyber bullying. According to the authors, the biggest potential risk is that cyber bullying activities have a very high risk of vulnerability for children and adolescents, as they are not able to assess the risks of their own cyber-victimization [Oonagh L. Steer1Peter J. R. Macaulay, Lucy R. Betts,].

And, finally, our attention was drawn from this book by an article in which the main attention of the authors is focused on the problem of aggression on dates in the online space. The authors identify three forms of online aggression that occur in romantic partners in adolescence: cyber stalking, revenge porn, and cyber bullying. As a result of the study, the authors build a generalized integrative model of the uniqueness of each form of network aggression, which allows them to identify and describe the reasons for involvement in these forms of aggression in romantic relationships [Chelsea Olson Amy Bellmore]. 
A large number of articles in the English literature are devoted to the use of smartphones. The study of this problem can be discussed in a little more detail. The authors introduced the concept of "problematic use of smartphones". However, they note that there is still no single generally accepted definition of this concept. In 2017, Kardefelt-Winther et al. defined the concept as a form of behavior characterized by compulsive use of a device that leads to various forms of physical, psychological or social harm. However, it seems to us that this concept can be attributed not only to smartphones, but also to any other type of Internet addiction. Therefore, in our further analysis of the works related to smartphone addiction, we will keep in mind other types of Internet addiction. Almost all authors who study this problem note that there are many negative consequences associated with excessive use of smartphones. Daniel L. KingaPaul H. Delfabbrob identified six main factors of disorders that occur in adolescents with smartphone addiction. This is a violation of everyday life, positive expectation, care, cyberspace-oriented relationships, excessive use and tolerance; symptoms of addiction, tolerance and abstinence, excessive use and violations of everyday life; violation of adaptive functions, orientation to virtual life, abstinence, tolerance; tolerance, problem avoidance, withdrawal, craving, negative life consequences, and social motivation; inability to communicate, loss of connectivity, inability to access information, and refusal of convenience; abstinence, lack of control/problems, tolerance/intervention.

The authors also highlight the personal problems that teenagers try to cope with by "escaping" to the Internet space. Note the main ones: increase your popularity and gain recognition and self-confidence, mitigate your depressive symptoms and relieve boredom or frustration [Elhai JD1, Dvorak R. D. 2, Levin JC3, Hall BJ4]; escape from problems, a way to solve psychological problems, reduce anxiety, maintain emotional intimacy with other people in an online virtual environment to compensate for the lack of interpersonal relationships in reality [Yen C.-F., Tang T.-C., Yen J.-Y., Lin H.-C., Huang C.-F., Liu S.C., Ko C.-H.]

This also includes premorbid states in social communication, such as social anxiety disorder, loneliness or other psychosocial problems, shyness and loneliness, low selfesteem and anxiety [Bianchi A., Phillips J. G., De Lisle S. M., Dowling N. A., Allen J. S.], high levels of neuroticism, which is associated with passivity and low emotional stability [Kim D., Lee Y., Lee J., Nam J. K., Chung Y]. Extroversion can also be one of the reasons for addiction, as smart phones allow you to expand your social circle.

The authors also highlight the socio-psychological factors that determine the propensity to depend on a smartphone. Different authors distinguish different factors. The most famous of these are the lack of peer support and the need for belonging [Adam $\mathrm{N}$ Joinson, Yen C.-F., Tang T.-C., Yen J.-Y., Lin H.-C., Huang C.-F., Liu S.-C., Ko C.-H.], as well as difficult relationships with parents and their lack of involvement in the lives and problems of teenagers (CrossRefGoogle Scholar Hwang and Jung; Kwon M., Kim D.-J., Cho H., Yang).

\section{Materials and Methods}

The question arises: why do some active Internet users become addicted, while others do not, and how does Internet addiction affect the personality of active users of social networks. In connection with this problem, under our leadership, A.V. Baguslavskaya conducted a research related to the study of the psychological characteristics of active users of social networks, that is, persons who spend a significant amount of time in social networks. 
The features of self-presentation in social networks and the features of the needs for communication and trust of active Internet users were studied. The study involved 100 respondents aged 15 to 25 years.

In terms of using a computer, the following picture is observed: first of all, users use it for personal communication and entertainment (26.6\%), a little less to replenish knowledge $(19.2 \%)$, then for work $(18.3 \%)$, and in Last but for business and professional contacts $(8.9 \%)$ (Chart number 1$)$

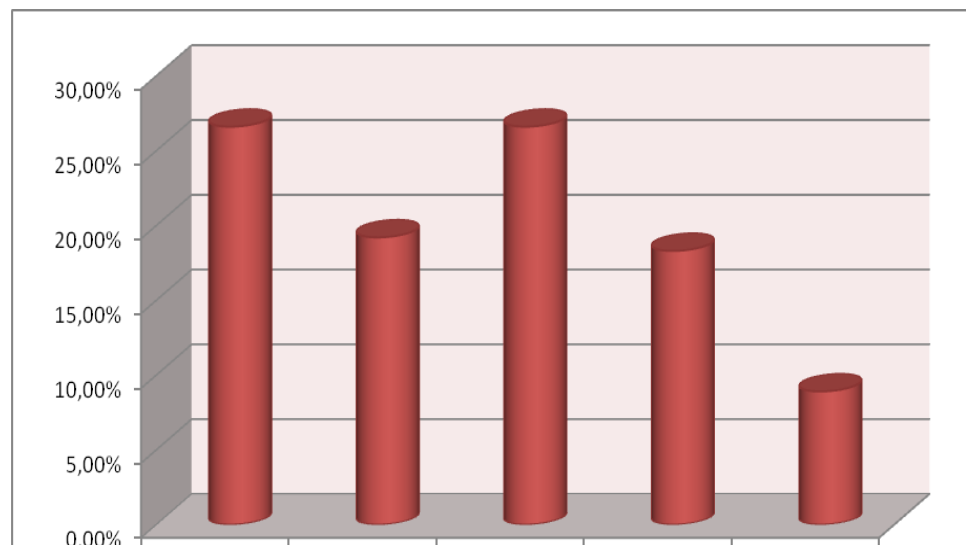

Fig. 1. 1 column - Personal communication; 2 column- Replenishment of knowledge; 3 column Recreation and entertainment; 4 column - Work; 5 column - Business contacts

The study consisted of two stages and, accordingly, had two hypotheses.

The first hypothesis was formulated as follows: the self-presentation of users of social networks is due to their personal characteristics. Depending on different personality traits, self-presentation strategies will vary significantly.

As you know, modern technologies allow a person not only to create the desired image for him, but also to change it infinitely and experiment with different images. Having chosen a suitable appearance, the user can use it and experience a new role for himselfherelf, even very different from the real "self image". However, when the gap between the real and ideal Self is too large, users can experience personal difficulties, and Internet communication only exacerbates them. The study of users' self-presentation was conducted on the website www.vkontakte.ru. 47 people participated this part of the study. The authors analyzed the statements about themselves and the features of self-presentation.

At this stage of the study, the following methods were used to study personal characteristics:

Personal questionnaire FPI, Personal Self-portrait test (J. Oldham and L. Morris); method of personal differential (adapted in the laboratory of V. M. Bekhterev); test to identify the level of self-esteem; author's questionnaire concerning a person's preferences for the Internet.

The purpose of the second part of the study was to study the interpersonal needs (in the field of communication) and the features of trust in themselves and others of active users of social networks, as well as to consider the relationship between these characteristics and the way of using a computer.

The main hypothesis of the second part of the study was the following assumption: the level of computerization of respondents depends on the level of their trust in themselves and others and interpersonal communication needs.

To do this, we used the previously created questionnaire of attitude to the computer and 5 ways of using the computer: Personal communication (communication on forums, chats, through ICQ, QIP, Skype, etc.); replenishment of knowledge (professional sites, articles, 
training on the Internet, etc.); recreation and entertainment (watching movies, listening to music, games, etc.); work (professional interests and tasks, development of programs, websites, earning money via the Internet, etc.); business contacts (communication with colleagues at work/school, business correspondence, development of joint projects via the Internet, etc.)

The following assumption was tested: the way a person uses a computer is related to the level of trust in him herself and trust in others and interpersonal communication needs.

Participants in this part of the study were 53 respondents of the average age group (1625 years).

The questionnaire data, together with the content analysis of the users' page in the social network "In Contact", were statistically processed using the statistical program Statistica 6.0

\section{Results}

Based on the cluster analysis, 2 groups of Internet users were identified in relation to social networks, and their personal characteristics were studied. The first group of users, which can be given the conditional name "Real", were distinguished by the presence of the following psychological characteristics: a high level of self-esteem, self-acceptance, selfconfidence, extroversion.

The second group of users, which we conditionally called "Virtual", showed signs of dependence on the Internet environment. From the first group, they are distinguished by a low level of self-esteem, the development of strong-willed sides and self-confidence, introversion.

As already noted, in the second part of the study, the subjects were asked to complete the following test methods: the method "Self-confidence assessment" (T. P. Skripkin); the method of J. B. Rotter "Interpersonal trust Scale" (translated, adapted and validated by S. I. Dostovalov); the questionnaire of interpersonal relations (V. Schutz); the author's questionnaire concerning a person's preferences for the Internet.

Then the correlation analysis of the obtained data was carried out.

\section{Discussion}

In the first part of the study, the "group of real "and the group of "virtual" users significantly differed from each other.

The "real" group noted that they would like to spend less time at the computer, communicate more with their friends and family. This group showed no signs of Internet addiction. In the social network "In Contact", these users usually showed a large number of their photos, information about themselves, their hobbies, interests, and had a fairly large number of contacts.

Subjects from the "virtual" group noted that they consider the computer an integral part of their lives. These people often equated virtual communication to real communication. According to the "Personal Self-portrait" test, people in this group were more likely to fall into the following types: "Hermit", "Sensitive", "Devoted", "Serious". These types, in particular, are also characterized by such personal characteristics as a small manifestation of emotions, low self-esteem, a tendency to analysis, criticality, and pessimism. On the site "In Contact", their pages are distinguished by the scarce information, secrecy, and the presence on the site of photos of other subjects (landscapes, cartoon personages, objects, animals) instead of the author's photo. 
This group of users either hid most of the information about themselves, or simply closed their page from outsiders.

Thus, we can say that the strategy of avoiding your " I " in social networks is carried out by: avoiding the publication of your photos and the publication of extraneous photos; indicating a small amount of information about yourself, or indicating negative information; restricting access to sections of your page; the absence of a page in the social network. These are some strategies for self-presentation of people who have an intrapersonal conflict between the "I am social" and the "I am ideal".

The general conclusion of the first part of the study is that, as expected, the selfpresentation of users of social networks is interrelated with their personal characteristics and inclinations, as well as with their attitude to the computer.

The correlation analysis of the data obtained in the second part of the study allows us to conclude that the level of computerization of Internet users is really related to the level of their self-confidence, especially in the professional and intellectual sphere. Respondents with high scores on these scales showed a low level of interest in computer activities. At the same time, the level of computerization had an inverse correlation with age.

The part of our hypothesis concerning the connection between the way the computer is used and interpersonal communication needs also turned out to be correct. The data obtained can be interpreted as follows: respondents with a pronounced business activity in relation to the computer, tend to belong to different groups, to be included, to be among people as often as possible, while they tend to accept others so that they, in turn, take part in their activities, show interest in them. However, these users may experience frustration and a certain personal conflict, coming from the desire to be in different groups and be in good, friendly relations with people, but at the same time the desire to separate, close in yourself, selectivity in establishing close relationships.

\section{Conclusion}

The study of the features of communication and trust of active Internet users allowed us to draw the following conclusions: highly active users of social networks, indeed, have a particularly low level of self-confidence in some areas (especially professional and intellectual). The way you use your computer is also important.

Thus, those who used a PC primarily for personal communication and entertainment were more likely to have a low level of self-confidence in general, and self-confidence in the ability to create relationships with others. In addition, this group of respondents had some problems in communication, in particular, they had contradictory behavior in the field of "control". Individuals with this feature, on the one hand, crave control over themselves, on the other hand, resist any attempts by others to guide them.

As the previous time, the opposite of this group was the group of respondents who use PCs mainly for work and knowledge acquisition.

These people were distinguished by high confidence in themselves in general and in most of the studied areas (intellectual, professional, in the ability to build relationships with others, to please representatives of the opposite sex). However, these individuals were also distinguished by the presence of interpersonal conflicts in the field of behavior, the meaning of which is the desire to be included in a large number of groups, to be among people as often as possible, to be in close and friendly relations with them, but at the same time, they felt the desire to separate, to close themselves from others.

Thus, a big and important question arises: whether Internet addiction comes first or there are some personal predictors leading to Internet addiction. The answer to this question requires more research. 


\section{References}

1. A.E. Voiskunsky, Psychology and the Internet (Akropolis, Moscow,2010)

2. L.S. Vygotsky, Sobr. soch. in 6 volumes (Pedagogika, Moscow, 1982-1984)

3. Child and Adolescent Online Risk Exposure (ed. Mchelle F. Wright) doi.org/10.1016/C2018-0-02272-0

4. Ikuko Aoyama, Online contact risk behaviors and risk factors among Japanese high school students. Child and Adolescent Online Risk Exposure. doi.org/10.1016/B978-012-818626-8.00007-4

5. Oonagh L. Steer, Peter J. R. Macaulay, Lucy R. Betts, John D. Ranney, The process of exploitation and victimization of adolescents in digital environments: the contribution of authenticity and self-exploration. Child and Adolescent Online Risk Exposure. doi.org/10.1016/B978-0-12-818626-8.00007-4

6. Michelle F. Wright, Tali Heiman, Dorit Olenik-Shemesh, Problematic internet use: causes, consequences, and future directions. Child and Adolescent Online Risk Exposure. doi.org/10.1016/B978-0-12-818626-8.00007-4

7. Chelsea Olson Amy Bellmore, Online aggression and romantic relationships in adolescence. Child and Adolescent Online Risk Exposure. doi.org/10.1016/B978-0-12818626-8.00007-4

8. Kardefelt-Winther et al., How does the time children spend using digital technology impact their mental well-being, social relationships and physical activity? An evidence-focused literature review Innocenti Discussion Paper 2017-02. doi.org/10.3109/16066359.2014.9353

9. Daniel L. Kinga, Paul H. Delfabbrob, Adolescent Addiction (Second Edition); doi.org/10.1016/B978-0-12-818626-8.00007-4

10. J.D. Elhai, R.D. Dvorak, J.C. Levin, B.J. Hall, Journal of Affective Disorders 207, 251259 (2016). doi: 10.1016/j.jad.2016.08.030.

11. C.-F. Yen, T.-C. Tang, J.-Y. Yen, H.-C. Lin, C.-F. Huang, S.-C. Liu, C.-H. Ko, Journal of Behavioral Addiction 6 (4), 708-717 (2017). doi.org/10.1016/j.cpr.2016.11.01012.

12. A. Bianchi, J.G. Phillips, Social Science Computer Review 1-19 (2014). doi: 10.11/77/0894439313508611

13. S.M. De Lisle, N.A. Dowling, J.S. Allen, Behavior and Information Technology 35(7), 520-525(2016)

14. D. Kim, Y. Lee, J. Lee, J.K. Nam, Y. Chung, Personal factors that predict susceptibility to dependence on smartphones: the behavioral inhibition system and activation, impulsivity and self-control PLoS One 11(8), (2016) doi: 10.1371 / journal.pone.0159788.

15. D. Kardefelt-Winther, A. Heeren, A. Schimmenti, A. Van Rooij, P. Maurage, M. Carras, ..., Y. Khazaal, Cyberpsychology and Behavior 7 (4) 479-486 (2004).

16. C.-F. Yen, T.-C. Tang, J.-Y. Yen, H.-C. Lin, C.-F. Huang, S.-C. Liu, C.-H. Ko, Journal of Behavioral Addiction 6 (4), 708-717 (2017) doi.org/10.1111/j.14401819.2008.01820.x

17. CrossRefGoogle Scholar Hwang and Jung Parental mediation regarding Children's Smartphone Use, Cyberpsychology, Behavior, and Social Networks 1-7(2017)

18. M. Kwon, D.-J. Kim, H. Cho, S. Yang, Journal of Psychology \& Behavioral Sciences 3 (1), 85-103 (2017). doi: 10.22492/ijpbs.3.1.06 